Dossier: El Quehacer de las Humanidades: Acción Social, Investigación y Metodologías e Innovación Tecnológica en la Docencia

\title{
El performance como herramienta de provocación epistemológica para el estudio de las humanidades en la Universidad de Costa Rica
}

\author{
Elvia Amador Rojas \\ Universidad de Costa Rica, Costa Rica \\ elvia.amadorrojas@ucr.ac.cr \\ https://orcid.org/0000-0001-5840-4559
}

Recibido: 3 de octubre de 2019

Aceptado: 15 de enero de 2020

Resumen: Esta investigación adquiere sentido en el marco transdisciplinario que puede establecerse entre las artes escénicas y el estudio de las humanidades, es quizá este puente un desafío para el campo de la epistemología. Es ésta una investigación desde las artes escénicas hacia las ciencias sociales, la performance como una provocación para reflexionar, evidenciar y valorar que la experiencia artística es en sí una forma de conocimiento.

Palabras clave: performance; provocación epistemológica; transdiciplinariedad; humanidades; Universidad de Costa Rica.

\section{Performance as an epistemological provocation tool for the study of the humanities at the University of Costa Rica}

Abstract: This research makes sense in the transdisciplinary framework that can be established between the performing arts and the study of the humanities, this bridge is perhaps a challenge for the field of epistemology. This is an investigation

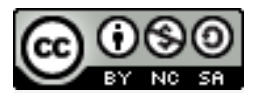

La Revista Estudios es editada por la Universidad de Costa Rica y se distribuye bajo una Licencia Creative Commons Atribución-NoComercial-CompartirIgual 3.0 Costa Rica. Para más información envíe un mensaje a 


\section{Especial: Profesores de Estudios Generales investigan}

from the performing arts towards the social sciences, performance as a provocation to reflect, evidence and value that the artistic experience is itself a form of knowledge.

Keywords: performance, epistemological provocation, transdiciplinarity, humanities, University of Costa Rica.

"Verum ipsum factum"1

Giambatista Vico

Este escrito no pretende ubicar la pertinencia del performance como herramienta didáctica, donde la "creatividad" ponga de manifiesto el nivel de aprehensión de conocimiento teórico que abordan las materias llamadas Humanidades en la Universidad de Costa Rica. Tampoco se cuestiona sobre el papel de las artes en las clases universitarias desde un enfoque humanista. No se trata de activismo político ni tampoco del ámbito terapéutico que cierto enfoque psicodramático podría formular para con el performance como herramienta dispuesta para algo más.

\section{Performance: conceptualización y transdiciplinariedad}

Podemos acercarnos sumariamente a la idea del performance desde las representaciones no convencionales surgidas con las vanguardias artísticas, particularmente el surrealismo. El performance como una práctica estética encuentra su origen entre el teatro, las artes visuales y las tradiciones rituales. Es una forma de conocimiento que utiliza el cuerpo como material central de su planteamiento expresivo o discursivo. Lo cierto es que este concepto se despegó

\footnotetext{
1 “La verdad es lo hecho mismo" Giambatista Vico (trad. personal).
}

\section{(c) (i) (2)}

La Revista Estudios es editada por la Universidad de Costa Rica y se distribuye bajo una Licencia Creative Commons Atribución-NoComercial-CompartirIgual 3.0 Costa Rica. Para más información envíe un mensaje a 
Especial: Profesores de Estudios Generales investigan

hace unos cuarenta años de esa univoca posibilidad artística y pasó a ser un caldo de cultivo para llenar necesidades expresivas e investigativas. Distintos saberes tomaron prestado al arte esta posibilidad estética de conocimiento.

La proliferación del uso del término performance en diversos rincones del lenguaje/conocimiento dificultan su conceptualización. Podemos definirlo de forma general como un arte vivo, en tanto el espacio es su soporte y su material fundamental es el cuerpo, pero existen muchas variantes dentro del performance como propuesta artística. Además, no es el arte el único campo que le toma para su estudio o como herramienta metodológica para investigar o ubicar otros fenómenos, por ejemplo, sociales.

Para tratar de dotar de un sentido preciso al performance es necesario comprender el carácter inestable del término. Diana Taylor, una de las más constantes teóricas del performance, así lo propone al identificar, entre otros, los siguientes puntos de inestabilidad:

1) No es un término aceptado universalmente para referirse a arte vivo o live art. "Algunos se refieren a proto-happenings, o "efímeros pánicos", o arte acción, o body-painting, o rituales Fluxus, entre otros nombres." (Taylor, 2011, p. 10)

2) El performance tiene trayectorias largas (para problematizar la concepción de orígenes o referencias) y círculos diversos de circulación. Algunos lo ubican desde el campo de las artes visuales, otras desde el teatro, otros en relación a necesidades expresivas específicas de los contextos por ejemplo represivos) Su finalidad es variada: artística, política o ritual. "Lo importante es resaltar que el performance surge de varias prácticas artísticas, pero trasciende sus límites; combina muchos elementos para crear algo inesperado, chocante, llamativo." (Taylor, 2011, p. 11)

3) Las prácticas varían según el contexto sociopolítico y éste a su vez determina la magnitud o impacto en la realidad que el performance visibiliza o invisibiliza.

La utilización del cuerpo como material central del performance es, quizá, el aspecto más valioso en cuanto a su derivación en una flexibilidad epistemológica considerable y que alimenta la fuerza de los tres puntos anteriores.

La Revista Estudios es editada por la Universidad de Costa Rica y se distribuye bajo una Licencia Creative Commons Atribución-NoComercial-CompartirIgual 3.0 Costa Rica. Para más información envíe un mensaje a 
Especial: Profesores de Estudios Generales investigan

Del mismo modo, la disputa Moderna por el espacio y la mirada producen una tensión epistemológica a la hora de abordar al performance.

Taylor considera que el performance es un acto de transferencia que permite que la identidad y la memoria colectiva se transmitan a través de ceremonias compartidas. Es decir, no implica solo la dimensión individual o la social sino todas las tensiones entre ellas. "Performance, como acto reiterado, hace visible otras trayectorias culturales y nos permite resistir la construcción dominante del poder artístico e intelectual" (Taylor, p. 19).

Estas razones dan fe de la imposibilidad de abarcar el estudio del performance desde un solo campo del conocimiento, puesto que es "simultáneamente un proceso, práctica, acto, episteme, evento, modo de transmisión, desempeño, realización y medio de intervención en el mundo." (Taylor, 2011, p. 28).

Sobre los estudios del performance, Prieto (2002), realiza un abordaje crítico proponiendo el performance y la teatralidad asociada a éste como instrumentos de análisis conceptuales de los fenómenos expresivos (sociales, políticos y culturales). Reconoce su utilidad como paradigma de análisis de la expresividad humana contemplando las transformaciones en los prototipos expresivos que surgen debido a fenómenos como la globalización, las migraciones y las construcciones identitarias complejas subyacentes.

Prieto (2002) encuentra que el performance y la teatralidad adquieren un papel preponderante para articular nuevas herramientas teóricas a partir de las existentes en los campos de la sociología, antropología, psicología y lingüística, por ejemplo. Estos nuevos modelos teóricos que se sugieren, al ser derivados de un fenómeno expresivo, contemplan otras formas de conocimiento que se articulan para analizarle o bien que le construyen como lente para ubicar un análisis de otros fenómenos individuales, sociales o relaciones entre ambos.

\section{(2) $(100$}

La Revista Estudios es editada por la Universidad de Costa Rica y se distribuye bajo una Licencia Creative Commons Atribución-NoComercial-CompartirIgual 3.0 Costa Rica. Para más información envíe un mensaje a 


\section{Provocación epistemológica}

Especial: Profesores de Estudios Generales investigan

Prieto (2002) enfatiza en el aporte del enfoque plural que permite el performance y en su potencial, en desarrollo en el ámbito académico al ser considerado en éste como lateral. "Se trata pues, de un campo emergente, transdisciplinario, intercultural, transfronterizo. Todavía hasta cierto punto marginal en el mundo académico." (párr. 40). Otros autores concuerdan con este punto de vista rescatando la pertinencia de otras formas de conocimiento en las nuevas construcciones teóricas y prácticas vitales.

McVittie (2015) en "The Poetics of Performance Knowledge", brinda un amplio cuestionamiento a las poéticas del conocimiento y sus variantes en torno a los sentidos como medios para acceder a la información. Contrasta una forma de conceptualización y expresión que prioriza lo ocular sobre lo háptico, y argumenta que cada una de estas formas de comprometer los sentidos conforman epistemologías poéticas distintas. Para McVittie, algunas modalidades de conocimiento calzan mejor que otras al pensar y escribir sobre ciertas prácticas.

Este investigador cuestiona el privilegio que ha tenido el sentido de la vista por sobre el tacto (percepción que involucra todo el cuerpo) dentro de las formas en que conocemos. Asimismo, enfatiza sobre las posibilidades que las metáforas establecidas en el performance aportan, en ese sentido, a la cognición. Para McVittie: "Las formas de escribir, y de hecho el pensamiento, pueden estar asociadas con modalidades sensoriales - esas capacidades con las que nos relacionamos y conocemos el mundo más allá de nosotros mismos." (McVittie, 2015, p. 72). Esta relación metafórica, agrega el autor, es parte de un conjunto más amplio de metáforas que rastrean diferentes tipos de saber a partir de diferentes modos de acceso al conocimiento empírico.

Las posibilidades de conocer con todo el cuerpo, sugeridas por el abordaje háptico, proyectan desafíos importantes para diferentes espacios de saber, como

La Revista Estudios es editada por la Universidad de Costa Rica y se distribuye bajo una Licencia Creative Commons Atribución-NoComercial-CompartirIgual 3.0 Costa Rica. Para más información envíe un mensaje a 
Especial: Profesores de Estudios Generales investigan

por ejemplo para la pedagogía tradicional, más cartesiana, donde solo lo probable y lo repetible tienen forma de conocimiento. En este sentido, las investigadoras, Bianciotti y Ortecho (2013), en el texto "La noción de performance y su potencialidad epistemológica en el hacer científico social contemporáneo", se abocan a la tarea de conceptualizar la noción de performance como objeto empírico y categoría analítica en las ciencias sociales y humanas y sus potenciales alcances en las formas de producción de conocimiento social.

Las autoras establecen un potencial epistemológico de la noción performance, resaltando su importancia en las ciencias sociales en cuanto al estudio de aspectos icónicos, corporales, performáticos, volitivos y afectivos aplicados tanto al individuo como a la cultura. Bianciotti y Ortecho (2013) plantean que, a partir de la emergencia y circulación de performance como noción, pero dirigido a ubicarse como constructo teórico aplicable a múltiples campos, se dan una serie de transformaciones onto-epistemológicas.

Para definir este proceso las autoras identifican que los tipos discursivos utilizados como soporte de significación en el campo de los estudios sociales y humanos han sido predominantemente de tipo lingüístico. Consideran oportuno cuestionar la especificidad, huelga decir "verbo centrista", de los soportes sígnicos empleados para la expresión de la ciencia occidental moderna de forma análoga a sus principios de objetividad, neutralidad, imparcialidad y las transformaciones que se requieren para aportar desde otros tipos de producción discursiva en términos de construcción semiótica y su vinculación con una matriz epistémica para incluir a todas las áreas del conocimiento en las posibilidades investigativas de estos campos.

El cuestionamiento de los espacios de producción de sentido que realizan las investigadoras abre la discusión epistemológica sobre otras formas de conocer en las áreas de ciencias sociales y humanas, en concordancia con las propuestas de McVittie y Prieto. La inclusión y recuperación de otras formas de representación 
Especial: Profesores de Estudios Generales investigan

y su reconocimiento, como soportes legítimos para la construcción -y vehiculización - del conocimiento social y humano, es una oportunidad para revisar una serie de cuestiones que, como se ha visto, atañen tanto a las dimensiones teórica y epistemológica como a las posiciones axiológicas que siempre las sostienen y subyacen. (Bianciotti y Ortecho, 2013, p. 136).

Se encuentra la necesidad de articular otras formas de construir sentido, de conocer. Biancotti y Ortecho comulgan con las propuestas de McVittie y Prieto en el sentido de debatir los principios desde donde se construyen los paradigmas epistemológicos en pro de ampliar nuestros límites y flexibilizar nuestros lenguajes. La proxemia y la croxemia como herramientas fundamentales en las artes escénicas, por ejemplo, pueden ser mecanismos muy importantes también en la comprensión de la manera en que accedemos a la información, ya no solo almacenada en nuestra "computadora central" sino en el cuerpo y sus relaciones con el entorno.

En virtud de esto, en "El performance como herramienta terapéutica y pedagógica", Azcona (2013) señala que, sin importar el enfoque, el performance es siempre una herramienta de autoconocimiento, autoexploración y que va de la mano con la experiencia personal del proponente (performer). La perspectiva de Azcona es la de un investigador-creador y como tal se posiciona en el fenómeno performance como una respuesta del cuerpo a su contexto y donde "Como consecuencia de las interrogantes surge una amplia gama de representaciones" (p. 47).

La diversidad de miradas, desde un punto de vista corpóreo, sobre un mismo fenómeno social, evidencian interrogantes y caminos de resolución alternativos que muchas veces la institucionalización de las formas de conocer nos limita. Pero allí donde solo se encuentra una manera de mirar, el performance abre el cuerpo a variantes tanto transdisciplinarias como ilimitadas.

\section{(c) (i) (2)}

La Revista Estudios es editada por la Universidad de Costa Rica y se distribuye bajo una Licencia Creative Commons Atribución-NoComercial-CompartirIgual 3.0 Costa Rica. Para más información envíe un mensaje a 


\section{Cuerpo y Universidad}

\section{Especial: Profesores de Estudios Generales investigan}

El cuerpo es un espacio fértil de conocimiento gratuito y obligatorio, que nos propone retos y una constante transformación individual. Queramos o no, debemos hacernos cargo de nuestro cuerpo, responsabilizarnos de su conocimiento. En el transcurso del siglo XX, los medios de comunicación y producción en masa cambiaron el curso de la humanidad, el capitalismo económico volcó la cotidianidad hacia el consumo. Los objetos y las prácticas relacionadas a ellos fueron alteradas por los medios de producción en masa. De esta forma, las trasformaciones económicas fueron realizando modificaciones significativas en cuanto a la vida diaria, proponiendo a los individuos construir el sentido de su vida alrededor del consumo. Esta serie de cambios propiciaron el surgimiento de nuevas formas de conocer, algunas quizá menos privilegiadas que otras, unas con más agencia que otras, algunas institucionalizadas y otras aún indómitas, como el cuerpo.

Ahora bien, siguiendo la propuesta de Taylor vale destacar que las universidades, en especial las estatales, siguiendo una lógica normal, se inscriben en el campo de acción de la institucionalidad del poder vigente. En general, se trata de instituciones que procuran cultivar individuos en concordancia con las necesidades que dicta su contexto social. En Costa Rica, por ejemplo, para contribuir con las transformaciones provocadas por este nuevo paradigma de sociedad, en 1940 se creó la Universidad de Costa Rica. En su estatuto orgánico, actualizado en 2005, la Universidad se propone como "una institución de educación superior y cultura" cuyos propósitos fundamentales son: "la enseñanza, la investigación, la acción social, el estudio, la meditación, la creación artística y la difusión del conocimiento" (Art. 1, Estatuto Orgánico de la Universidad de Costa Rica, p. 1).

\section{(c) (i) (2)}

La Revista Estudios es editada por la Universidad de Costa Rica y se distribuye bajo una Licencia Creative Commons Atribución-NoComercial-CompartirIgual 3.0 Costa Rica. Para más información envíe un mensaje a 
Especial: Profesores de Estudios Generales investigan

Ya desde 1957, se propone la Escuela de Estudios Generales como pieza fundamental de la reforma universitaria donde se consigna la primacía del ser humano, la exaltación de los valores esencialmente humanos y el ideal de cultura humanística que han de anteponerse siempre a la especialización profesional. En concordancia con este ideario, Estudios Generales se plantea como unidad académica interdisciplinaria de las áreas de Artes y Letras, Ciencias Básicas, y de la Facultad de Ciencias Sociales.

El Curso Integrado de Humanidades de la Universidad de Costa Rica (...) se centra en formar ciudadanos conocedores de su realidad, que puedan enfrentar el mundo desde diversas ópticas, mejorando la pertinencia y la calidad de su contribución profesional a la sociedad. (Benavides y Núñez, 2016, p.3.).

La formación especializada en cada profesión se percibe como insuficiente para enfrentar los retos que la sociedad demanda. Así, se prevé la necesidad de un individuo integral con conciencia del mundo y de su responsabilidad como profesional en él. $Y$ enfatizado por estas intenciones éticas y sociales de la filosofía universitaria, donde prima una visión humanista, es que, en 1973, en una modalidad de trabajo interdisciplinario, surgieron los Seminarios Participativos. En ellos se integran, al grupo de materias constitutivas de los Estudios Generales (Comunicación y Lenguaje, Filosofía y Pensamiento e Historia de la Cultura) más la materia Artística o Repertorio:

Desde esta posición epistemológica va a configurarse un modelo de acercamiento a la realidad, que actúa como una especie de pauta o matriz amplia y abstracta, en la cual caben los procedimientos y técnicas más específicas que se vinculan con la lógica del quehacer educativo desde una determinada concepción (Coordinación de los Seminarios Participativos, 1998, citado por Benavides y Núñez, 2016, p. 7).

Al proponer este modelo, el trabajo interdisciplinario y la búsqueda de nuevos paradigmas de educación son los objetivos fundacionales de la metodología de los Seminarios Participativos dentro de los cursos de Humanidades. Serán en

\section{(a) $(\Theta \odot$}

La Revista Estudios es editada por la Universidad de Costa Rica y se distribuye bajo una Licencia Creative Commons Atribución-NoComercial-CompartirIgual 3.0 Costa Rica. Para más información envíe un mensaje a 
Especial: Profesores de Estudios Generales investigan

consecuencia espacios cuya intención es variar la posición epistemológica hacia la apertura de nuevos aprendizajes y formas de conocimiento.

\section{Un detonador de advenimientos desde las "teorías políticas":}

el caso del performance en el Curso Integrado de Humanidades, opción Seminario Participativo

Los Seminarios Participativos en Estudios Generales buscan la integración, la interdisciplinariedad, la criticidad, la creatividad y la evaluación permanente. Dentro de esta dinámica, a la vez, el curso de Apreciación de Teatro traza un reto al integrarse junto con las diferentes disciplinas alrededor de las Teorías Políticas como eje temático del Seminario. En esta conjugación, se identifican en especial como puntos de encuentro: el origen del teatro y su condición de espacio de socialización de ideas, maneras de ver e interpretar el mundo, nociones de realidad, la utilización del lenguaje connotativo y sus alcances, las construcciones poéticas y su política, etc.

Asimismo, existe la necesidad de que el estudiantado se apropie de los conceptos adquiridos en el Seminario con respecto a la integración de las materias de Historia de la Cultura, Comunicación y Lenguajes, Filosofía y Apreciación de Teatro, a partir de un panorama general de las teorías políticas que se pretenden desarrollar. Una posibilidad pedagógica es capitalizar a través del teatro y sus posibilidades expresivas, los contenidos del curso. Puesto que uno de los contenidos de la asignatura de Apreciación de Teatro es el de arte conceptual y sus diferentes manifestaciones en las artes escénicas se considera oportuno el acercamiento a una de estas: el performance. En consecuencia, se integran los temas del Seminario y se estimula a los estudiantes a apropiarse del conocimiento tomando un rol activo, desde las artes. De esta manera se vierten los conocimientos adquiridos a nivel integral, a la vez que se apoderan de los propios,

\section{(c) (i) (2)}

La Revista Estudios es editada por la Universidad de Costa Rica y se distribuye bajo una Licencia Creative Commons Atribución-NoComercial-CompartirIgual 3.0 Costa Rica. Para más información envíe un mensaje a 
Especial: Profesores de Estudios Generales investigan

accionando desde el performance. Se desarrolla una experiencia significativa para experimentar y producir discursos críticos desde el juego con las posibilidades escénicas del ritual, la convención y la reminiscencia.

A partir de la concepción de performance como acción artística se desafía a los estudiantes a realizar una muestra escénica, donde tanto la provocación como el planteamiento o juego con la estética, cobren un papel principal. Se da énfasis a que no es el objeto sino el sujeto el elemento constitutivo de esta obra artística. Es decir, ellos y sus cuerpos son los protagonistas y a la vez la obra en sí. Se solicita que todos los recursos que se utilizan sean seleccionados cuidadosamente para llenar de significado potentes imágenes escénicas. Las posibilidades pedagógicas o su alcance expresivo o "creativo", únicamente visto como alternativa a lo memorístico, son realmente muy superficiales confrontadas a todas las posibilidades que el performance ofrece como forma de conocimiento, como se ha evidenciado en las valoraciones teóricas anteriores.

Entonces, se reta a los estudiantes a seleccionar alguno de los temas vistos durante el seminario, u otro en tensión con el contexto, que les atraviese emocional o intelectualmente. Es indispensable que les interpele, que les moleste o les incomode. A partir de esta provocación surgen invocaciones al pasado, desplazamientos en cuanto a posiciones cómodas que las teorías políticas nos inculcan, y una serie de fenómenos escénicos difíciles de describir en palabras, pues, como se ha señalado, el performance, al igual que otras artes escénicas, constituye un detonador de advenimientos convocados en el ritual de la presencia.

La gran variedad de los performance resultantes ocurre gracias a la diversidad que existe en este tipo de grupos de Humanidades, donde son habitualmente ochenta estudiantes de diferentes grupos etarios, lugares de procedencia, migrantes (extranjeros o nacionales), carreras de empadronamiento, etc. La asignación faculta una reflexión polémica con respecto a múltiples ámbitos

La Revista Estudios es editada por la Universidad de Costa Rica y se distribuye bajo una Licencia Creative Commons Atribución-NoComercial-CompartirIgual 3.0 Costa Rica. Para más información envíe un mensaje a revistaestudios.eeg@ucr.ac.cr. 


\section{Especial: Profesores de Estudios Generales investigan}

desarrollados durante el curso. Se despliegan temáticas, abordajes metodológicos y conceptuales que abarcan desde la problemática venezolana, la realidad nicaragüense, la despolitización de la política, la democracia como negocio, la indiferencia ante los problemas ajenos como un valor costarricense, las distorsiones en las construcciones identitarias latinoamericanas, la crisis de las humanidades enfocada en la problemática universitaria, la falta de agenciamiento que sufre una gran parte de la población costarricense.

Las consecuencias de esta provocación no son predecibles, como sucede desde ciertos paradigmas educativos muy alejados del espíritu de los Estudios Generales. Pero este escrito no constituye un manifiesto pedagógico del desarrollo del potencial creativo para ilustrar los conceptos de las asignaturas "legitimadas" por la academia, pero también este punto se toca cuando irrumpe la dinámica de un performance. Entonces, la pregunta: ¿Cómo genera el performance una provocación epistemológica para el estudio de las humanidades en la Universidad de Costa Rica? Late en esta pregunta un pensamiento del empirismo popular recogido por Taylor (2009) en un estudio realizado en la comunidad de Tepoztlán, Morelos: "las instituciones van y vienen (...) la gente permanece" (p. 211).

Bajo esta premisa se aborda, entonces, el performance en el espacio del Seminario. Éste nos permite reflexionar desde los cuerpos como espacio de conocimiento. Concede al estudiantado construir conocimiento valorando su presencia, sus experiencias de vida; recurriendo a los cuerpos como testimonios de vida, de cultura, de humanidades.

\section{Performance: un minúsculo triunfo universitario}

Cómodamente, desde las butacas, que son parte del presupuesto estatal, observamos. Un estudiante al fondo de un espacio vacío camina cinco pasos hacia nosotros, mirando hacia el suelo. Sujeta su pesadísima mochila como si se

\section{(c) (i) (2)}

La Revista Estudios es editada por la Universidad de Costa Rica y se distribuye bajo una Licencia Creative Commons Atribución-NoComercial-CompartirIgual 3.0 Costa Rica. Para más información envíe un mensaje a 


\section{Especial: Profesores de Estudios Generales investigan}

le fuera la vida en ello, se muestra pensativo. Se detiene. Saca de su mochila una piedra pesada, áspera, le raspa sus manos. La coloca en el suelo. Amarrada a ella vemos un pequeño rótulo que dice "montañas". El estudiante respira profundo y nos deja escuchar un suspiro como rugido de volcán. Abandona la roca en el suelo con su rótulo. Continúa su camino hacia nosotros. A los dos pasos se detiene nuevamente. Abre su mochila. Mira su contenido por siete segundos. Saca una roca aún más grande y pesada que la anterior. La mira con detenimiento. Asiente con su cabeza como si le respondiera. Lentamente la deja sobre el piso, con pesar. Mira un momento el letrero que lleva puesto: "mi historia" dice... El estudiante avanza cuatro pasos precipitados. Ahora se detiene a pesar suyo. La mochila aún pesa demasiado para continuar. Rápidamente la abre y una roca más cae, casi le pisa los pies. El sonido que produce su golpe le duele en los oídos. Su etiqueta dice "amigos". El estudiante mira atrás. Tiembla al mirar el contenido de la mochila. La cierra dolorosamente. Nos mira. Avanza...dos pasos, tres más, lentos, largos como su camino. Se detiene. Saca otra roca, una magna. Al sacarla de su mochila cae al piso, de rodillas, llora desconsoladamente. Su título dice: "familia". Se levanta a ojos cerrados y progresa hacia nosotros. Corre cinco pasos más. Abre los ojos. Mira atrás. Trata de convencerse. Conquista. Continúa. Una última parada de viacrucis. Saca un pañuelo y se enjuta el rostro. Nos mira feroz. Por los ojos se le salen un millón de improperios y de preguntas. Saca una piedrecita más, una minúscula. El epígrafe dice: "yo". Suspira como cuando el mar quiere alcanzar al sol. Le abandona. Triunfa hacia nosotros. Toma asiento para acompañarnos cómodamente mirar a otro estudiante en su recorrido.

De pronto, el milagro, la reacción impredecible los cuerpos frente al performance de su compañero: Unos treinta estudiantes de zonas rurales y otros cuantos del Valle Central abandonan su butaca y en una coreográfica acción le buscan para abrazarlo y animarlo, aunque sea prácticamente un desconocido. Algunos otros compañeros esconden sus lágrimas entre las piedras de sus

\section{(c) (i) (2) (2)}

La Revista Estudios es editada por la Universidad de Costa Rica y se distribuye bajo una Licencia Creative Commons Atribución-NoComercial-CompartirIgual 3.0 Costa Rica. Para más información envíe un mensaje a 


\section{Especial: Profesores de Estudios Generales investigan}

mochilas. Incontables estudiantes tras él. ¿Y nosotros? ¿Dónde estuvo nuestra mirada? ¿En la ortografía de las inscripciones? ¿En el número de sus pasos? No, probablemente en sus ojos y las alas que lleva encerradas en el pecho.

Parece ser que existe un conocimiento generado por esta experiencia que no se escribió en el examen final, ni se obtuvo de los textos propuestos en el programa del curso. Un conocimiento que nació en el cuerpo, se escribió en el cuerpo y se aprendió con todos los sentidos. Desde las artes escénicas se establecen puentes entre conocimiento racional y el empírico. El arte del performance permite al cuerpo no sólo explorar y encontrar conocimiento preexistente fuera de él, sino que el cuerpo mismo es a la vez medio y objeto del conocimiento.

\section{Coda}

La gran variedad de teorías críticas del siglo XXI nace, en muchos casos (Foucault, Adorno, Benjamin, Rancière, etc.) en la exploración de un espacio incierto que irrumpe en las fronteras entre política y estética. La constitución de los fenómenos sociales y su relación con los disfraces que adquiere el poder son dispositivos potentes de estas teorías que exploran las posibilidades del "conocimiento del cuerpo" (Taylor, McVittie, Prieto).

Es posible que desde las artes estemos frente a un advenimiento, una provocación epistemológica que revise desde la disputa cartesiana nuestra manera de conocer, que nos permita desincribirnos de las ideologías dominantes, ya obsoletas, y nos regrese a las posibilidades gratuitas y obligatorias de conocer. El performance como una alternativa contemporánea transdisciplinaria del "verum ipsum factum", tal vez el giro de la performance: la anhelada repatriación del cuerpo.

\section{(c) (i) (2)}

La Revista Estudios es editada por la Universidad de Costa Rica y se distribuye bajo una Licencia Creative Commons Atribución-NoComercial-CompartirIgual 3.0 Costa Rica. Para más información envíe un mensaje a 


\section{Bibliografía}

\section{Especial: Profesores de Estudios Generales investigan}

Azcona, A. (2013) El performance como herramienta terapéutica y pedagógica. Efímera Revista. Volumen 4. Número 5, pp. 46- pp. 49. Recuperado de: http://www.efimerarevista.es/efimerarevista/index.php/efimera/article/view/35/42

Bazurro, L. (2015). Cuerpo, performance, conflicto: hacia una estética del reconocimiento moral. Resonancias No. 1. Diciembre 2015, pp. 1- pp. 38.

Benavides, C. y Núñez, J. (2016). Enseñanza participativa y cogestiva: la experiencia de los Seminarios Participativos. En el dossier: La enseñanza de las humanidades: aproximaciones metodológicas. Revista Estudios, número especial (1). Universidad de Costa Rica, pp. 1-pp. 25.

Bianciotti, M y Ortecho, M. (2013). La noción de performance y su potencialidad epistemológica en el hacer científico social contemporáneo. Tabula Rasa. Número 19, pp 119- pp. 137.

Dussel, E. (1994) Debate en torno a la ética del discurso de Apel, diálogo filosófico norte-sur desde América Latina. Siglo Veintiuno Editores. México.

McVittie, F. (2002) The poetics of performance knowledge. Journal Performance Research. Volumen 20, pp. 72- pp. 77.

Prieto, A. (2002) En torno a los estudios del performance, la teatralidad y más. Performancelogía, s.p. Recuperado de: http://performancelogia.blogspot.com/2007/08/en-torno-los-estudios-delperformance.html

Taylor, D. (2009) Performance e Historia. Apuntes de Teatro (131). Escuela de Teatro. Facultad de Artes de la Universidad Católica de Chile. (pp.105- pp. 123). Recuperado de: https://repositorio.uc.cl/bitstream/handle/11534/4640/000539909.pdf?sequence=1

Taylor, D. y Fuentes, M (2011). Estudios avanzados de performance. México: FCE, Instituto Hemisférico de Performance y Política, Tisch School of the Arts, New York University, pp. 7- pp. 30

\section{(C) $(00$}

La Revista Estudios es editada por la Universidad de Costa Rica y se distribuye bajo una Licencia Creative Commons Atribución-NoComercial-CompartirIgual 3.0 Costa Rica. Para más información envíe un mensaje a 